\title{
Who Has Access to Mobile Devices in an Online Opt-in Panel? An Analysis of Potential Respondents for Mobile Surveys
}

\author{
Melanie Revilla ${ }^{\star}$, Daniele Toninelli ${ }^{\dagger}$, Carlos Ochoa ${ }^{\ddagger}$ and \\ Germán Loewe*
}

*RECSM - Universitat Pompeu Fabra, Spain, melanie.revilla@upf.edu, tUniversity of Bergamo, Italy, daniele.toninelli@unibg.it,

${ }^{\ddagger}$ Netquest, Spain

\begin{abstract}
In most countries the spread of mobile devices in the general population has increased very quickly in the last years, changing people's habits of accessing and using the web. Because of this, if one wants to involve respondents who access the web with the new devices, it is necessary to adapt web surveys to these devices. Nowadays, even if some probability-based online panels exist, the large majority of web surveys are done by means of non-probability-based panels (also called 'opt-in' or 'access' panels). People volunteer to participate in these panels. Thus, we can expect that the spread of mobile devices in these panels differs from the spread of mobile devices in the general population and is probably higher. However, little is known about the exact spread of different mobile devices (tablets and smartphones) within the population of panelists in access panels. Moreover, little knowledge has been acquired about which combination of devices panelists have, in general and in different countries. However, this is crucial information, since access panels represent the majority of web surveys and the participation of the panelists in these surveys is conditioned by the equipment they own. Therefore, in this chapter we study data
\end{abstract}

\section{How to cite this book chapter:}

Revilla, M, Toninelli, D, Ochoa, C and Loewe, G. 2015. Who Has Access to Mobile

Devices in an Online Opt-in Panel? An Analysis of Potential Respondents for Mobile Surveys. In: Toninelli, D, Pinter, R \& de Pedraza, P (eds.) Mobile Research Methods: Opportunities and Challenges of Mobile Research Methodologies, Pp. 119-139. London: Ubiquity Press. DOI: http://dx.doi.org/10.5334/bar.h. License: CC-BY 4.0. 
from the Netquest online panel to get a more precise idea of the proportion of potential respondents in access online panels who would participate to surveys through mobile devices. The aim is mainly to evaluate the current spread of devices and their combination in a set of countries not studied before: Spain, Portugal and Latin American countries.

\section{Keywords}

Opt-in web panel, web surveys, mobile device ownership, mobile device access, Netquest

\section{Introduction}

It is clear that the spread of mobile devices (in particular smartphones and tablets) in the general population has increased very quickly in the last years, changing people's habits of accessing and using the web. A simultaneous quick increase of the active mobile Internet usage was observed. Worldwide, the mobile Internet penetration grew from $7 \%$ in 2008 to $23 \%$ in 2012 and $29 \%$ in 2013 (Statista 2014). According to the Statista (2014) study, the mobile Internet penetration is expected to overtake the fixed-broadband penetration in 2017 (reaching 54\% and 51\%, respectively). In some countries, this overtaking is already happening: for example, in terms of usage, according to StatCounter Global Stats (August 2014), ${ }^{26}$ the mobile has overtaken the fixed-broadband Internet usage in India (70.4\% vs $28.2 \%$ ), South Africa (55.7\% vs $38.7 \%$ ) and Saudi Arabia (51.2\% vs 40.5\%). In 2013, the mobile usage represented 25\% of the overall web usage, according to Smart Insights (2014) and KPCB (2014). This corresponds to an increase of $14 \%$ in comparison to the previous year. In particular, according to KPCB (2014), in Europe the mobile access is $16 \%$ of all web usage $(+8 \%$ in comparison to the previous year), and in North America it represents $19 \%$ of all web usage $(+11 \%$ in one year). StatCounter Global Stats (2014) confirms these findings: the percentage of desktop Internet traffic was 63.6\% in October 2014 (-32 percentage points compared to January 2011), whereas for mobile usage the percentage has grown rapidly from the $4.3 \%$ registered on January 2011 to $29.8 \%$ in October 2014 (+25.5 percentage points). In this same month of October 2014, tablets accounted for $6.53 \%$ of global Internet usage, whereas this percentage, just 12 months before, was $4.54 \%$. Thus, an increase of 1.99 percentage points was observed for tablet-based Internet use.

\footnotetext{
${ }^{26}$ StatCounter is a web analytics service that tracks over three million web sites worldwide. Every month, billions of page views of these tracked web sites are analyzed, recording characteristics of the web usage such as use of browser or of mobile devices. For further information, see: http://gs.statcounter.com/faq.
} 
Several factors contributed to this spreading process: for instance, the generally decreasing costs of mobile web connection or the improved quality of networks. But this trend is expected to be further encouraged by the wider distribution of mobile devices characterizing most countries. This process of a wide spread of mobile devices in web usage, according to recently observed data, will probably continue in the near future. Because of this, many researchers started thinking that web surveys needed to be adapted to these new devices. For instance, de Bruijne and Wijnant (2013: 483) claim that if the use of mobile devices is already considered a 'serious new alternative [...] for web-based selfadministered surveys', probably, with more developed technologies for both smartphones and tablets, in the close future it will become 'not only an alternative way to reach respondents, but perhaps even an indispensable one'.

Nowadays, even if some probability-based online panels exist (e.g. the Knowledge panel in the USA, the LISS panel in the Netherlands, the ELIPSS panel in France or the German Internet Panel), the large majority of web surveys are done by non-probability-based panels, also called 'opt-in' or 'access' panels. Because people volunteer to participate in these panels, we can expect that the spread of devices in these panels differs from the spread of devices in the general population and is probably higher. However, little is known about the exact spread of different mobile devices (tablets and smartphones) for people registered in access panels across time and in different countries. Also, little is known about which combination of devices panelists in access panels have at their disposal: how many of them have only a PC, only a mobile device (and which one) or a combination of both a PC and one or several mobile devices?

This is crucial information, since this kind of panels represents the majority of web surveys and since the participation of the panelists in these surveys is conditioned by the equipment they own. Indeed, access panels institutes/companies normally do not provide panelists who do not have a piece of equipment with that piece of equipment so that they can still participate in the surveys, contrarily to what probability-based panels usually do. Therefore, to get an idea of the proportion of potential mobile respondents in access online panels, information is needed about the current spread of such devices within panelists in these panels.

In this chapter, we will use the Netquest online panel data to evaluate the current spread of devices and their combination in a set of countries not studied before: Spain, Portugal and five Latin American countries (Argentina, Brazil, Chile, Colombia and Mexico). The next section will summarize what is already known about this topic, focusing on the state of the art of the current Internet coverage around the world and, more specifically, on the mobile web access penetration. In the following section, we will provide new evidence about the spread of mobile devices in the Netquest panel, studying both the proportion of panelists who own or have regular access to PC and mobile devices (smartphones and tablets) and the combinations of devices the panelists have. Then we will study whether there are significant differences between the groups 
of panelists who have only a PC and the ones who own at least one mobile device or own no devices at all and between the panelists who own only mobile devices and the others. Finally, the last section will summarize and discuss the main results, together with the limitations of this work and with some ideas to further develop this research.

\section{Internet coverage and mobile web access}

The Internet coverage is evolving very quickly. According to the latest data available (updated on December 31,2013), the worldwide penetration of Internet, considering an estimated population of 7.18 billion people, is $39.0 \%$ (source: Internet World Stats 2014). The same percentage, updated on June 30, 2012, was $34.3 \%$. This means that the coverage of the worldwide population has increased by 4.7 percentage points in just one year and a half. If we consider a longer time range, the Internet penetration for the worldwide population increased by $676.3 \%$ from 2000 to 2014 (the increase percentage between 2000 and 2012 was 566.4). Nevertheless, this general trend varies a lot by world region. In fact, the Internet coverage percentage ranges from the $21.3 \%$ registered in Africa to the $31.7 \%$ observed in Asia, up to the $68.6 \%$ in European countries and to the $84.9 \%$ in North America. The growth rates from 2000 to 2014 are also very different, ranging from the $177.8 \%$ observed in North America to the $5219.3 \%$ registered in Africa. If we take a more detailed look, even within the same region, the observed penetration rates of Internet varies a lot: for example, in Europe the minimum penetration observed is $41.8 \%$, registered for Ukraine, and the highest one is $96.5 \%$, for Iceland. In Figure 1, the Internet penetration rate by country is represented.

Nevertheless, one can ask the following question: if the Internet coverage increased so quickly in the last few years, what about the mobile access to the web? A lot of studies show that the mobile web penetration increased a lot in the last years too. According to a Eurobarometer study (Fuchs \&Busse 2009), $31 \%$ of the European population had access to a mobile Internet device in 2007, which is 5 percentage points higher than in 2005. Nielsen Mobile (2008) also highlights the growing importance of the mobile access phenomenon. In the first quarter of 2008, there were 254 million of mobile subscribers in the US; this subscription number generated US $\$ 1.7$ billion in revenue, an amount that had quickly increased if compared to the US $\$ 5$ billion in total revenue observed in the entire year of 2007.

Coming to closer times, in December 2011,35\% of EU citizens owning a personal mobile phone had access to the Internet through their mobile phones (Eurobarometer 2012). According to other research developed by Statistics Netherlands (2012), the mobile access rates continued to grow very quickly thereafter. In the Netherlands, $96 \%$ of the 12-75 years old used Internet in 2012, and from 2007 to 2012 the percentage of these users who accessed the 


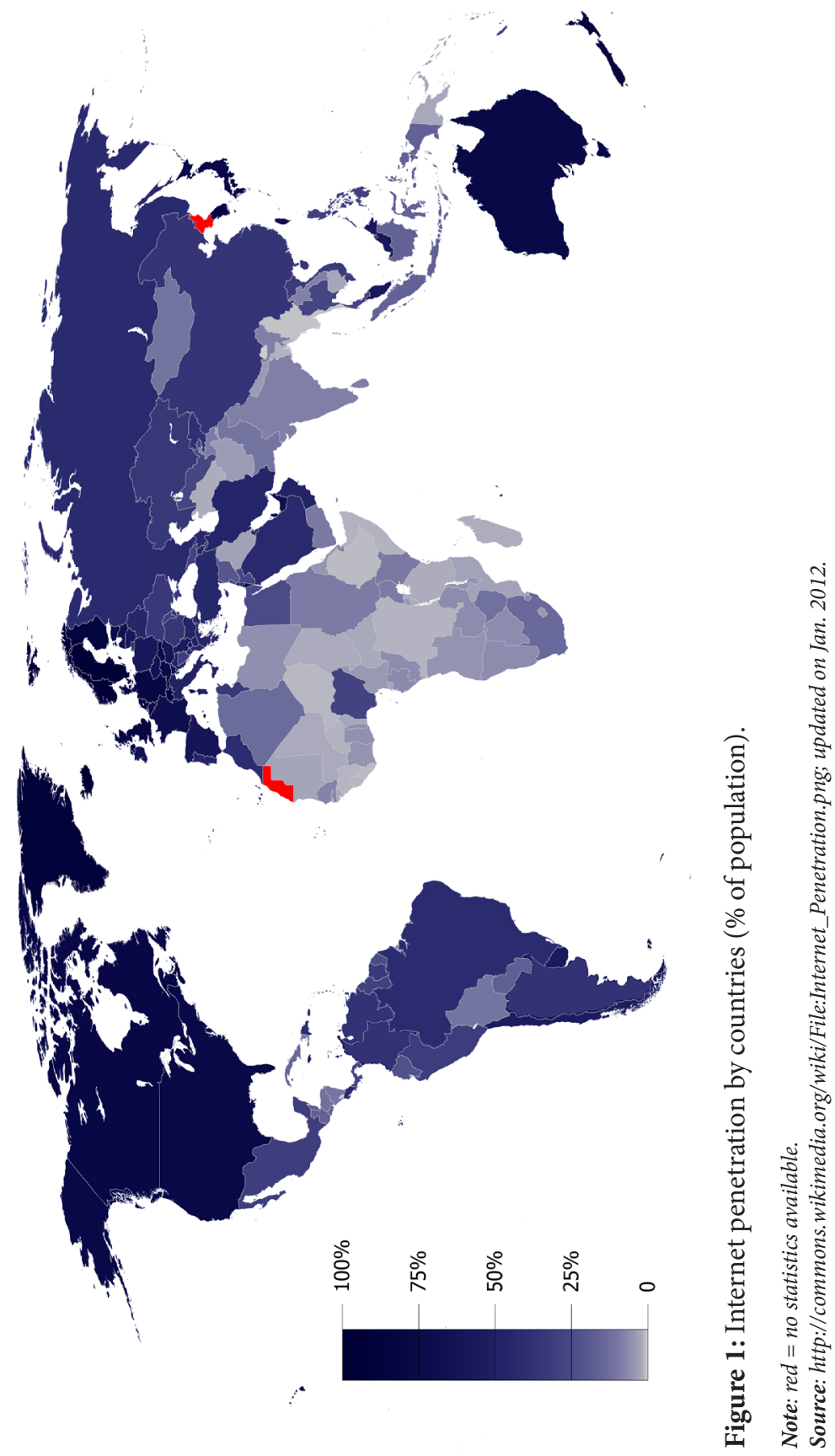


Internet by mobile devices has tripled: $60 \%$ of Internet users accessed the web by means of mobile devices in the three months before they carried out the survey. In comparison to the previous year, a growth of 10 percentage points was observed. The growth is particularly high for young people: in 2007, $21 \%$ of the 12-25 years old regularly used mobile devices to go online, whereas in 2012 , the same category increased to $86 \%$ (27\% of the $12-75$ years old people accessed Internet via mobile phones, $11 \%$ via tablets). Focusing on the different devices, in 2012 the preferred ones were mobile phones (small and handy, used by $47 \%$ of mobile Internet users, $66 \%$ of them daily), but tablets (19\%) were also regularly used (Statistics Netherlands 2012). Nevertheless, there is still a non-negligible percentage of Internet users (e.g. $40 \%$ in the Netherlands) who do not use mobile devices to access the web. This is mainly because they do not need to connect themselves to the Internet if they are outside home or outside their workplace, or due to the connection's costs. Regarding this last aspect, it was highlighted in a Eurobarometer (2012) study that about $43 \%$ of mobile Internet users limit their mobile Internet use due to concerns about charges. The most concerned about mobile Internet charges are Belgian (62\%), Irish (60\%) and Greek (60\%) people, whereas lower percentages of concern are registered in the Netherlands (29\%), Sweden (29\%) or Luxembourg (28\%).

Further data about the spread of mobile web show that between January 2012 and September 2013, access to the web by mobile web browser increased from $8.49 \%$ to $17.81 \%$ worldwide (StatCounter Global Stats 2013). de Bruijne and Wijnant (2013) studied what kind of connection was used to access Internet by analysing the CentERPanel data collected in the Netherlands: $28.7 \%$ of the panel members involved ( 14 years and older) accessed to web via smartphones, and $19.1 \%$ via tablets. This is consistent with the KPCB (2014) statement that $30 \%$ of all mobile users are smartphone users. More recently, StatCounter Global Stats (2014) observed that the worldwide use of mobile devices to surf the Internet has increased by $67 \%$ from September 2013 to the same month of 2014. If we consider the global mobile data traffic, the growth registered in 2013 is of $81 \%$ (Cisco VNI Mobile 2014). Cisco VNI Mobile (2014) also forecasted that the global mobile data traffic will grow nearly 11-fold between 2013 and 2018. This corresponds to a compound annual growth rate of $61 \%$.

If these are the general figures, the situation changes a lot when considering different countries or regions. Analysing the mobile web penetration in earlier years, Fuchs and Busse (2009) noticed that the rates were very different from country to country: in 2007 in Europe, rates were varying from 18\% in Romania and Bulgaria to $49 \%$ in Luxembourg. The same authors noticed that no clear pattern was observed for mobile web access rate: the coverage was mostly driven by various activities of network service providers in different markets. If we consider more recent data, according to a Eurobarometer (2012) study which referred to December 2011 in comparison to the first part of that year (March-April 2011), a marginal increase of the proportion of 


\begin{tabular}{|l|r|r|r|r|r|r|}
\hline & \multicolumn{2}{|c|}{ October 2012 } & \multicolumn{2}{c|}{ October 2014 } & \multicolumn{1}{c|}{$\begin{array}{c}\text { Desktop } \\
\text { change } \\
\text { (\% points; } \\
\text { 2014 vs 2012) }\end{array}$} & $\begin{array}{c}\text { Mobile } \\
\text { change (\% } \\
\text { points; 2014 } \\
\text { vs 2012) }\end{array}$ \\
\hline Argentina & 95.6 & 4.5 & 79.9 & 20.1 & -16.3 & $+15,6$ \\
\hline Brazil & 94.5 & 5.5 & 74.7 & 25.3 & -20.9 & +19.8 \\
\hline Chile & 94.6 & 5.4 & 60.9 & 39.1 & -35.7 & +33.7 \\
\hline Colombia & 96.8 & 3.2 & 79.3 & 20.7 & -18.1 & +17.5 \\
\hline Mexico & 91.7 & 8.3 & 64.0 & 36.0 & -30.2 & +27.7 \\
\hline Portugal & 96.2 & 3.8 & 78.3 & 21.7 & -18.6 & +17.9 \\
\hline Spain & 90.1 & 9.9 & 56.6 & 43.4 & -37.1 & +33.5 \\
\hline
\end{tabular}

Table 1: Desktop and mobile web usage by country (2012 and 2014).

respondents who own a mobile phone subscription allowing them to access the Internet was observed between both periods (+1\%). But, again, this general figure varies a lot if one compares different countries: for the UK, Slovenia, Finland and Malta, for example, a growth of $6 \%$ was observed, similar to the level registered in Luxembourg $(+5 \%)$; on the other hand, a fall in mobile Internet access was observed in Portugal $(-12 \%)$ and in the Czech Republic $(-7 \%)$. According to the same study, the percentage of EU citizens owning a personal mobile phone who had access to the Internet through such a kind of device is highest in Sweden (63\%), the UK (58\%) and Slovenia (57\%), whereas this situation is still less common in Bulgaria (13\%), Portugal (16\%), Italy (17\%) and Romania (18\%).

Table 1 helps in focusing the analysis of the current web usage (and of its spread in the last few years) specifically on the countries that will be studied in this chapter: Argentina, Brazil, Chile, Colombia, Mexico, Portugal and Spain. In particular, the table shows the percentages of desktop and mobile web usage, ${ }^{27}$ comparing October 2014 with October 2012 (data source: StatCounter Global Stats 2014).

The Internet traffic by device has changed a lot even in the last two years only. If in October 2012, the desktop accesses covered more than $90 \%$ of web traffic in the seven considered countries (with a peak of more than $96 \%$ in Colombia and Portugal), after 24 months the same percentage dropped by more than 15 percentage points. But these general figures are only the reflection of the different levels of changes observed in different countries. The drop is indeed mostly relevant in Chile (from 94.6\% to 60.9\%), in Mexico (from 91.7\% to $64.0 \%$ ) and in Spain (from $90.1 \%$ to $56.6 \%$ ), whereas it is observed at a lower

\footnotetext{
${ }^{27}$ StatCounter tracks tablets as a separate category. Nevertheless, in Table 1 the 'Mobile devices' data also include tablets: we merged the two categories for the sake of clarity.
} 
level for example in Argentina (from 95.6\% to 79.9\%), in Portugal (from 96.2\% to $78.3 \%$ ) or Colombia (from $96.8 \%$ to $79.3 \%$ ).

One of the possible consequences of this is the considerable increase in terms of mobile usage of the web observed for Chile (from $5.4 \%$ to $39.1 \%$, corresponding to +33.7 percentage points), Spain (from $9.9 \%$ to $43.4 \%$; +33.5 p.p.) and Mexico (from $8.3 \%$ to $36.0 \%$; +27.7 p.p.). In 2014, the spread of mobile traffic shows lower levels (between $20 \%$ and 26\%) for Brazil $(25.3 \% ;+19.8$ p.p.) Portugal (21.7\%; +17.9 p.p.), Colombia (20.7\%; +17.5 p.p.) and Argentina (20.1\%; +15.6 p.p.).

To sum up, a lot of research has been made showing that overall a fast increase is observed in most countries in Internet coverage and mobile access to the web. Nevertheless, the necessity of further research is emphasized by the following factors: first, the noticeable differences in mobile Internet coverage/ usage penetration rate and in its patterns over time from country to country (e.g. Eurobarometer 2012; Fuchs \& Busse 2009; StatCounter Global Stats 2014); second, the potential different purposes and factors that push people to the mobile usage ${ }^{28}$; and third, most previous results refer to the general population, but we can expect differences for mobile spread between the general population and the participants of access online panels.

Some agencies or services, such as StatCounter, already provide detailed and updated data concerning web usage (see Table 1), but this information does not really fit the purposes of our research for two main reasons. First, StatCounter data are focused on web traffic; thus, for instance, the same mobile users can be counted several times as they access several web pages with the same device. Second, our study is mainly focused on panelists and their coverage by mobile access, not on the general population.

Online panel suveys need to know specifically what the spread of mobile devices within panel members is and who the persons susceptible to answer (or not answer) to the surveys through mobile devices are. We assume that the spread of mobile devices will be even larger in this specific population of web panelists, but how much larger? And are there groups of panelists with different levels of mobile coverage? Moreover, the urgency to develop a more detailed research increases with the fact that mobile devices are not only replacing more traditional devices like PCs (desktop or laptops), but are also complementing them in many cases, such that more and more individuals own not only one device but a combination of devices. For example, it was highlighted that 'mobile Internet is used as a complimentary mean for accessing the web; respondents who have mobile Internet have Internet in their homes as well' (Eurobarometer 2012: 9). Thus, it also becomes relevant to understand which combinations of devices the panelists have regular access to. Very little

\footnotetext{
${ }^{28}$ For example, in Japan the mobile web is very well spread because it is the main way to watch television and access Internet, whereas mobile web access is less important in other countries where there are already landline infrastructures for both TV and Internet (Okazaki 2007).
} 
is known about this topic, in particular in some geographical areas like Latin America. That is why, in the following parts of this chapter, we will focus on the spread of mobile devices for participants to an access online panel in seven countries that have not been studied much before from this perspective.

\section{New evidence from the Netquest panel}

Netquest (www.netquest.com) is an online fieldwork company founded in 2001 that started its first online panel in 2006, in Spain. Currently, it is also present in Portugal and Latin America, with more than 450,000 panelists truly active $^{29}$ and 4 millions of completed surveys every year. What differentiates Netquest from other online access panels is that it is the only one in the Latin American and South European region accredited with the ISO 26362 quality standard. Netquest recruits people corresponding to the profile it needs to participate in the panel. The potential respondents are selected from different databases of users of many websites who agreed to receive emails. Once they have joined the panel, for each completed survey, panelists get points that they can exchange for gifts. While most of the surveys sent by Netquest were developed for computers (desktops and laptops), the company noticed an increasing demand from both some clients and some panelists to use mobile devices to design or answer the surveys (with direct requests or comments and with numbers of attempts to complete the surveys through mobile devices). In order to get more information on this phenomenon, Netquest provided the necessary data to study in a more in-depth manner the spread of mobile participation within its panelists to determine which strategy to adopt for the years to come. The results of the analyses are presented in the next subsections. By using these data, we get new evidence about the spread of mobile access in Central and Latin America, and in Portugal and Spain, and for a very large number of panelists.

\section{Owning different devices}

Netquest has a system of continuous profiling of its panelists by means of different modules. Each module deals with a different topic. When respondents are filtered out of a survey, they get one of these profiling modules. Using this system, Netquest accumulates information about as many panelists as possible in order to be able to target specific populations and/or to model different behaviors or attitudes. The order in which respondents get the modules depends on the level of priority Netquest attributes to the corresponding topic. Starting

${ }^{29}$ We define as 'truly active' a member who participated to at least one survey sent by Netquest in the last 12 months. Data updated in November 2014. 
from the end of 2012, Netquest introduced two modules: one about the equipment of the respondents, in which they are asked, among other things, if they have a desktop PC, a laptop and/or a tablet; and one about new technologies, in which one of the questions asks if they own a smartphone.

Figure 2 shows the percentages over time of panelists who own the different devices by country. ${ }^{30}$ The data are aggregated by quarter. The first data correspond to the first quarter of 2013 (except for Spain, where the modules started later). Even if some of the information was available for the end of 2012, it is not shown in the graphs, because it was incomplete. It should be clear that the information at different points in time is based on different panelists. Thus, the number of respondents to these modules varies from month to month and from country to country (cf. Appendix 1). Nevertheless, overall these results represent a huge amount of panelists for which this information is known: more than 190,000 for the first module, and more than 250,000 for the second one.

The first chart of Figure 2 shows the average of all countries. It highlights that the proportion of panelists who own a smartphone (79.9\%) is as high as the one of those who have a laptop $(80.7 \%)$ in the first quarter of 2013. Both are about 10 percentage points higher than the proportion of panelists who own a desktop PC (71.9\%). Moreover, the proportion of smartphone owners seems to have slowly overtaken the percentage of laptop owners (see the data for the last quarter in the same chart: $82.0 \%$ for smartphones vs $76.6 \%$ for laptops). Generally, the proportion of panelists with a tablet is much lower (around 30-40\%), but it is also increasing over time, even very quickly in some countries (e.g. in Chile, where the percentage is more than doubled in just one year). On the contrary, the proportion of panelists owning a desktop PC tends to decrease: on average, it loses about five percentage points in one year, and this trend is confirmed in all the single countries. Even if there are differences across countries in the observed percentages of smartphone and tablet owners, clearly a large majority of panelists owns mobile devices, and we can reasonably expect that this phenomenon will continue to spread further in the future (at least on the tablet side). On the other hand, Figure 2 already suggests that probably fewer and fewer panelists will own a computer (at least a desktop one); these findings seem to confirm the forecasts of some studies that are expecting the mobile web penetration to overtake the fixed broadband penetration in the next few years (Statista 2014), as seen in section 1.

\section{Combination of devices}

Figure 2 only provides information about owning different devices, without allowing to discriminate if respondents own only one device or a combination

${ }^{30}$ The questions asked are: 'Do you have a desktop PC?', 'Do you have a laptop?', 'Do you have a tablet?', and 'Do you have a smartphone?'. 


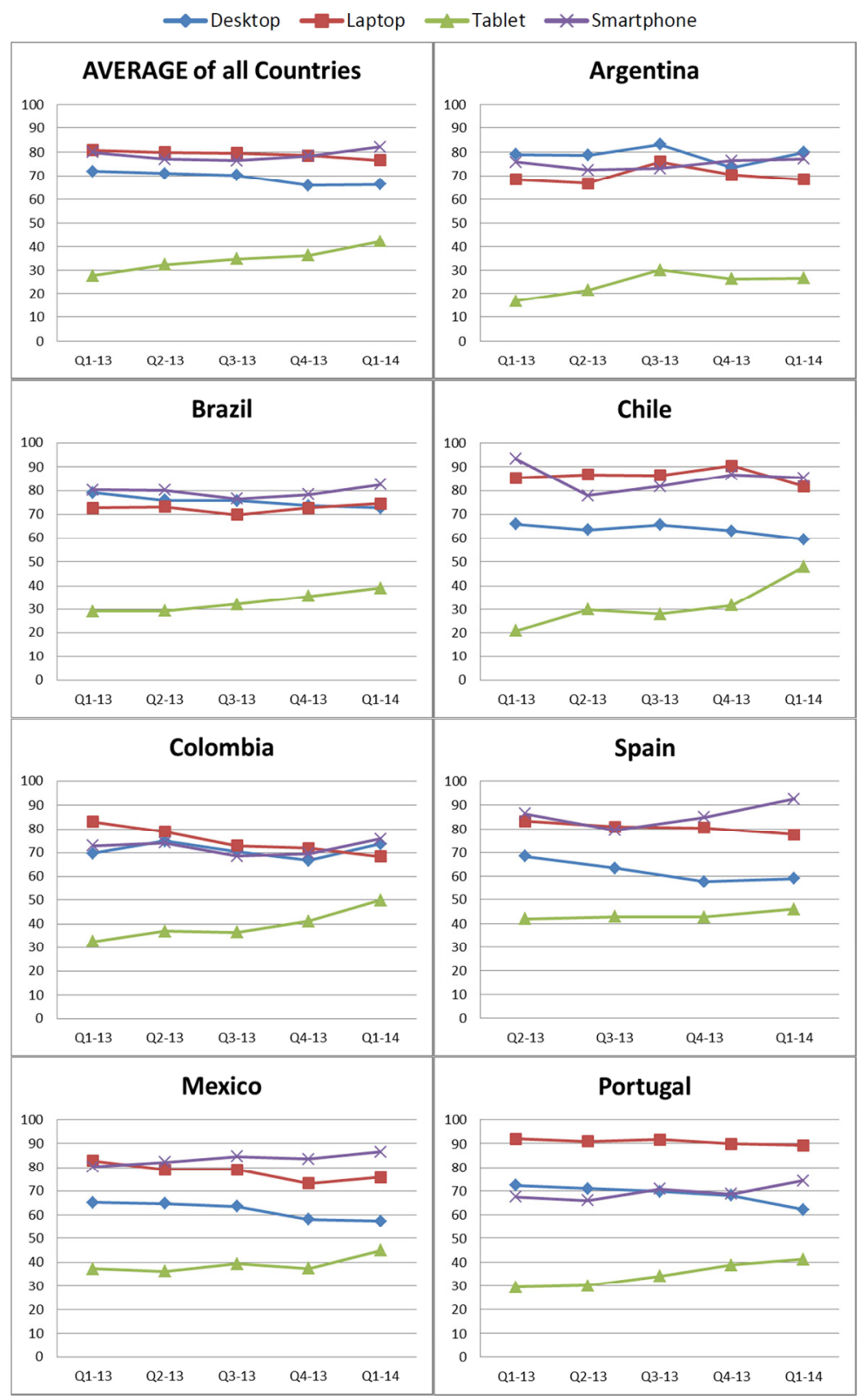

Figure 2: Percentages of panelists who own different devices.

Note: Q1-13 means the first quarter year of 2013, Q2-13 means the second quarter year of 2013, etc.; Average $=$ non-weighted average of the values of the different countries. 
of two or more devices. To get this more detailed information, we need to cross the data from the two modules previously mentioned. In doing so, we are reducing the number of observations at each point in time quite a lot. For this reason, instead of looking at each quarter year, we have aggregated the data of the different quarters, starting with the second quarter year of 2013 because there are not enough data before. Figure 3 presents the percentages of panelists who answered both modules and who have only one device or a combination of two or three (the two kinds of PC, fixed and laptop, are shown combined for the sake of clarity).

Again, Figure 3 shows that, even if there are some variations in the size of the proportions across countries, overall, the same main trends are observed. In all countries, the largest percentage corresponds to the combination of a computer and a smartphone ( $42.3 \%$ on average). The following largest category is the combination of the three devices (computer + tablet + smartphone, $28.9 \%$ on average). On average only $20.3 \%$ of panelists own only one kind of device. Therefore, the majority of potential respondents can really choose to answer surveys through one or another device. However, there is still a non-negligible part of panelists who have only a computer (from $12.9 \%$ in Chile to $24.1 \%$ in Portugal; $17.7 \%$ on average). Almost no panelists have only a tablet $(0.2 \%)$ and very few of them have only a smartphone $(2.4 \%$ on average, with a maximum level observed for Mexico: 3.5\%) or have no devices and for instance go to an Internet café or complete the survey at work (on average 1.6\%; this percentage rises to $2.2 \%$ for Mexico and to $2.3 \%$ for Colombia).

Looking at the evolution over time of owning these devices, Figure 4 shows the differences (in percentage points) between the proportions of panelists with one, two or three devices, comparing the last available point in time (Q1 of 2014) and the first one (Q2 of 2013).

Figure 4 shows that the ownership of different devices has evolved quite a lot in about one year: for example, the proportion of panelists with three devices increased considerably (7.7 percentage points on average, with a peak of 14.7 percentage points for Colombia), while on the other hand the proportion of PC-only owners mainly decreased in all countries (by 7.8 percentage point on average, with a maximum of 11.9 percentage points lost for Colombia).

\section{Additional access to different devices}

So far, we focused the analysis on whether or not panelists owned different types of devices. However, we should note that panelists can also have access to some devices even if they do not own them: for instance, they can have regular access to a computer at their workplace or at a library. In order to take this important aspect into account, we studied data from a survey completed by around 1,000 Netquest respondents within each country (quotas were set by age and gender to obtain, in each country, a sample representative of the complete panel 


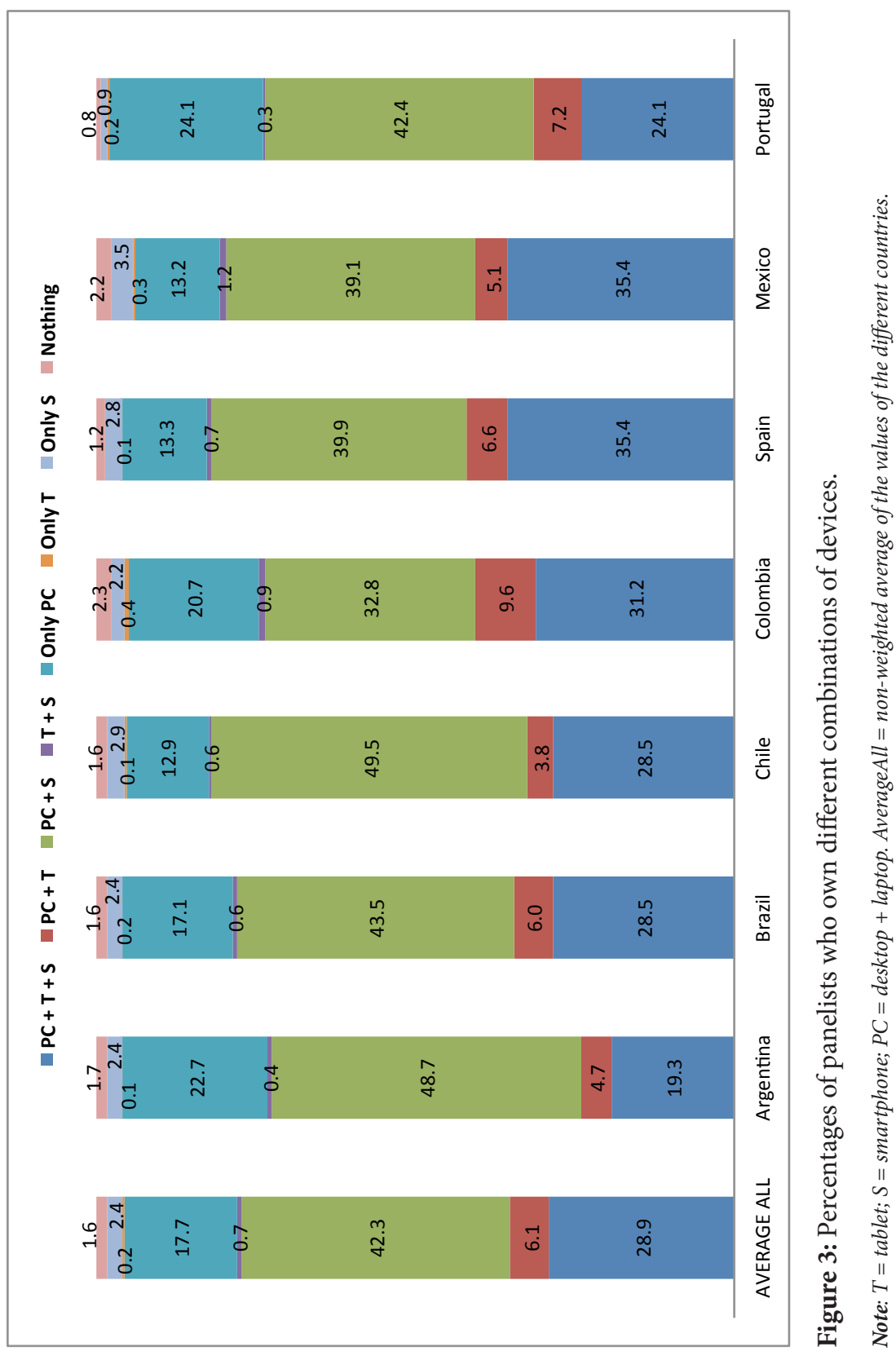




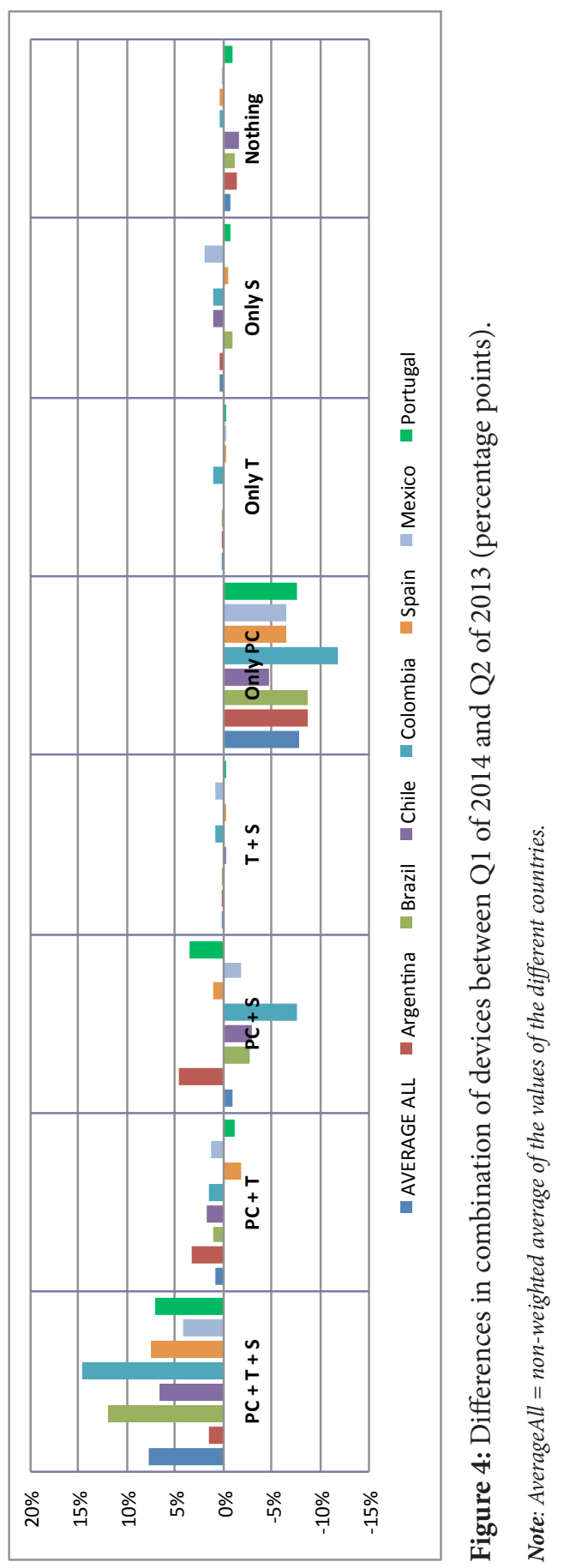


population). Respondents were asked if they owned different devices, and, in the case where they answered 'no', they were asked if they had a regular access to these devices. In Table 2 the additional percentages of respondents who have regular access to the devices, even though they do not own them, are shown.

Table 2 shows that there is an additional percentage of respondents, between $10.5 \%$ (observed in Spain) and 19.7\% (in Chile), who have regular access to a desktop PC, even though they do not own one; the unweighted average over countries is $14.3 \%$. Regarding laptops, $8.9 \%$ of respondents (unweighted general average) have access to one, in spite of not owning one: the lowest percentage is observed for Spain (4.9\%), and the highest one for Colombia (12.9\%). The highest percentage of access to a device without owning it is registered for tablets (16.3\%, general unweighted average; ranging from $10.8 \%$ in Portugal to $22.2 \%$ in Colombia); the additional usage for smartphones is only $5.7 \%$ (from $2.1 \%$ for Spain to $9.2 \%$ for Colombia).

From these results, we can presume that at least part of the considered panelists could be susceptible to answer surveys using devices that they do not own but regularly have access to. However, it can also happen that they have access to these devices in places or at times which will not allow or encourage them to participate in surveys. Therefore, it is difficult to estimate the real exact spread of the availability of different devices among panelists. This would need to be further studied.

In any case, we can conclude that overall, by not allowing respondents to answer the surveys through mobile devices, one would really exclude very few panelists for coverage issue, since very few do not have a computer (fixed or laptop), and even fewer do not have at least a regular access to a computer. Nevertheless, the panelists may decide to take part or not in a survey depending on the possibility to answer by means of different devices (including tablets and

\begin{tabular}{|l|r|r|r|r|}
\hline & \multicolumn{1}{|c|}{ Fixed PC } & \multicolumn{1}{c|}{ Laptop } & \multicolumn{1}{c|}{ Tablet } & \multicolumn{1}{c|}{ Smartphone } \\
\hline Argentina & 11.8 & 11.6 & 17.6 & 8.8 \\
\hline Brazil & 15.2 & 10.8 & 12.6 & 4.9 \\
\hline Chile & 19.7 & 6.8 & 19.6 & 4.3 \\
\hline Colombia & 11.7 & 12.9 & 22.2 & 9.2 \\
\hline Spain & 10.5 & 4.9 & 12.0 & 2.1 \\
\hline Mexico & 13.3 & 9.2 & 19.3 & 5.1 \\
\hline Portugal & 17.9 & 6.2 & 10.8 & 5.6 \\
\hline Average All & $\mathbf{1 4 . 3}$ & $\mathbf{8 . 9}$ & $\mathbf{1 6 . 3}$ & $\mathbf{5 . 7}$ \\
\hline
\end{tabular}

Table 2: Additional percentages of respondents who have regular access to the devices.

Note: Average All = non-weighted average of the values of the different countries. 
smartphones) and according to their preferences for these devices, since most panelists have the choice between at least two devices (and about $25-35 \%$ of them even between three devices). Further research is needed in this direction. Besides, even if it is a small group that would be excluded, this group could be very different from the rest of the panelists; thus the impact on the representativeness of the panel may be problematic. Therefore, in the next section we compare the characteristics of panelists who own different devices.

\section{Differences across groups: logistic regression analysis}

In this section, by means of two logistic regressions, we aim at understanding to what extent there are differences in the characteristics of groups of panelists who differ in terms of ownership of devices. In particular, we focus on the following main available variables: gender (dummy variable: $1=$ men), age (in categories), education (from lower to higher diploma; categories vary for different countries) and number of household members (numeric). In order to see which variables really affect the ownership of different devices, we first study the effect of the explanatory variables mentioned above on the fact that respondents own only a PC rather than at least one mobile device or no device at all. Table 3 presents the coefficients of this first logit.

According to the results shown in Table 3, in all countries there is a significant effect of age (higher probability to have only a PC for older respondents) and of education (lower probability to have only a PC for more highly educated respondents). Gender has a significant effect in Colombia, Spain, Mexico and Portugal, but not in Argentina, Brazil and Chile. Generally, whether it is significant or not, the gender's effect is negative, meaning that men are less likely to

\begin{tabular}{|l|c|c|c|c|c|c|c|}
\hline $\begin{array}{c}\text { Own only } \\
\text { a PC }\end{array}$ & Argentina & Brazil & Chile & Colombia & Spain & Mexico & Portugal \\
\hline Men & -0.24 & -0.12 & -0.27 & $-0.31^{\star}$ & $-0.64^{\star *}$ & $-0.51^{\star *}$ & $-0.43^{\star *}$ \\
\hline Age & $0.35^{\star *}$ & $0.32^{\star *}$ & $0.56^{\star *}$ & $0.26^{* *}$ & $0.44^{\star *}$ & $0.33^{\star *}$ & $0.42^{\star *}$ \\
\hline Education & $-0.35^{\star *}$ & $-0.50^{\star *}$ & $-0.33^{\star *}$ & $-0.50^{\star *}$ & $-0.41^{\star *}$ & $-0.19^{\star *}$ & $-0.41^{\star *}$ \\
\hline $\begin{array}{l}\text { No. } \\
\text { household }\end{array}$ & 0.07 & $0.13^{\star *}$ & -0.05 & 0.05 & $-0.20^{\star}$ & 0.08 & -0.01 \\
\hline Constant & -0.94 & -0.69 & $-1.75^{\star *}$ & 0.18 & -1.08 & -0.99 & -0.73 \\
\hline PseudoR & 0.0499 & 0.0527 & 0.0765 & 0.0459 & 0.0940 & 0.0592 & 0.0602 \\
\hline No. obs. & $\mathrm{N}=1000$ & $\mathrm{~N}=1011$ & $\mathrm{~N}=1000$ & $\mathrm{~N}=1001$ & $\mathrm{~N}=1002$ & $\mathrm{~N}=1005$ & $\mathrm{~N}=1000$ \\
\hline
\end{tabular}

Table 3: Logit of respondents who own only a PC versus the others.

\footnotetext{
Note: ${ }^{*} p<0.05 ;{ }^{*} p<0.10$; No. household $=$ number of persons in the household; No. obs $=$ number of observations.
} 


\begin{tabular}{|l|c|l|l|l|l|l|l|}
\hline $\begin{array}{c}\text { Own only } \\
\text { a mobile } \\
\text { device }\end{array}$ & Argentina & Brazil & Chile & Colombia & Spain & Mexico & Portugal \\
\hline Men & 0.06 & -0.50 & 0.31 & -1.44 & -0.32 & -0.67 & -0.52 \\
\hline Age & -0.14 & -0.15 & -0.17 & -0.17 & -0.05 & -0.34 & 0.01 \\
\hline Education & $-1.34^{\star *}$ & -0.39 & $-0.50^{\star *}$ & -0.32 & $-0.64^{\star}$ & $-0.38^{\star *}$ & $-0.61^{\star}$ \\
\hline $\begin{array}{l}\text { No. } \\
\text { household }\end{array}$ & $0.25^{\star *}$ & -0.11 & $-0.46^{\star}$ & 0.06 & -0.29 & 0.06 & $0.26^{\star *}$ \\
\hline Constant & -0.71 & -1.25 & 0.10 & -2.55 & -0.44 & 0.06 & -2.26 \\
\hline No. Obs. & $\mathrm{N}=1000$ & $\mathrm{~N}=1011$ & $\mathrm{~N}=1000$ & $\mathrm{~N}=1001$ & $\mathrm{~N}=1002$ & $\mathrm{~N}=1005$ & $\mathrm{~N}=1000$ \\
\hline
\end{tabular}

Table 4: ReLogit of respondents who own only mobile devices versus the others.

Note: ${ }^{*} p<0.05 ;{ }^{*} p \leq 0.10$; No. household $=$ number of persons in the household; No. obs $=$ number of observations.

own only a PC. The number of persons in the household has a significant effect only in two countries: Brazil (positive effect) and Spain (negative effect). Thus, overall, panelists who own only a PC differ from panelists with at least one kind of mobile device or no device at all in terms of age and education, and, in the majority of the countries, also in terms of gender.

Second, we study the respondents who own only mobile devices (smartphones, tablets or a combination of both) versus the others. Because the proportions of respondents who own only mobile devices are very small in each country, a classic logistic regression may lead to biased estimates. Instead, we use the RELOGIT command in Stata (Tomz, King \& Zeng 1999). ${ }^{31}$ The results of the analyses are shown in Table 4.

Table 4 shows that age and gender do not have any significant effect in any of the countries analyzed. On the contrary, education has a significant negative effect in Argentina, Chile and Mexico $(\mathrm{p}<0.05)$ and an effect on the edge of significance in Spain and Portugal $(\mathrm{p}=0.10)$. This means that in most countries, less educated respondents are more likely to have only mobile devices. Thus, allowing panelists to answer through mobiles devices and adapting surveys to facilitate their completion on mobile devices may favour the participation of less educated people, who have a higher probability of owning only mobile devices. Finally, the number of persons in the household has a significant positive effect in Argentina and Portugal and a significant negative effect in Chile. On the one hand, the positive effect may be linked to the fact that the

31 As defined by its authors, 'RELOGIT is a suite of programs for estimating and interpreting logit results when the sample is unbalanced (one outcome is rarer than the other) [...] RELOGIT estimates the same logit model as the -logit- command, but with an estimator that gives lower mean square error in the presence of rare events data for coefficients.' The program implements the procedures proposed by King and Zeng (1999a; 1999b). 
more people there are in a household, the higher the need for communication and the more devices are needed if the different members want to be able to connect to the Internet at the same time or want to have more independence in their communication. On the other hand, it may be linked to the fact that the cost per person of having a $\mathrm{PC}$ and fixed Internet connection is lower in a larger household. Also, if the household is larger, it is more probable that at least one of its members needs to have a PC (e.g. to work or study). Thus, the larger the household is, the lower the probability of having only mobile devices.

\section{Conclusions}

The spread of mobile devices increased very quickly in the last couple of years and we can expect that this trend will continue. Therefore, researchers and online panels users have started to pay interest both to the new opportunities and to the new challenges that mobile devices could offer them. Previous research has started to study the spread of the phenomenon by mainly focusing on web coverage, on the mobile penetration in a general population or on the analysis of mobile web usage. The growing interest generated by mobile access and usage of the web is confirmed by some experiments that were implemented about how to adapt questionnaires to these new devices, mainly smartphones and tablets. However, some of the preliminary results are based on only small samples of panelists. Moreover, some countries were not considered in previous research, even if the results can also strongly vary depending on the territorial context. Besides, these phenomena are developing and spreading so quickly that the results from two or three years ago may be already out of date. On the other hand, there is a real demand for more information about these topics from web panels, which have to face the current lack of knowledge and do not know exactly what the best strategies are for the future. That is why, in this chapter, we tried to provide some new evidence about the potential for the use of mobile web in surveys for online commercial panels like Netquest, taking into account different countries not studied in-depth before: Spain, Portugal and some Latin American countries.

Firstly, we have investigated the proportions of panelists who own different devices across different periods and we have seen that, even if the results differ across countries, overall, a very large proportion of panelists own mobile devices, in particular smartphones. This proportion increased quickly in less than one and a half year, whereas the proportion of desktop PC owners tended to decrease. Besides, there is also a non-negligible proportion of panelists who have access regularly to the devices, even though they do not own them. Therefore, a really large proportion of the panelists can be considered as potential mobile web respondents. However, our results also show that a majority of panelists own not only one but a combination of several kinds of devices, PC and mobile. Thus, they really can choose through which device to answer surveys. This means that the preferences for answering surveys using different devices 
need to be studied to get a more precise idea of the need for mobile surveys. Our results only show that there is a large potential. This potential is also linked to the characteristics of the panelists who own different devices. Comparing different groups of panelists based on their access to mobile devices, we found significant differences in terms of the main background variables (age and education) between respondents who own only a PC versus the others. We also found significant differences between the respondents who own only mobile devices versus the others in terms of education and, in some countries, household size. This all suggests that, even though mobile web respondents may still represent a relatively small group, it is crucial for the representativeness of a survey to include and involve them. Besides, the evolution over time suggests that this group will keep growing very quickly.

Further interesting questions are: how is it possible to implement the adaptation of a survey to a mobile mode in a cost-effective way? And how is it possible to reach this objective while allowing, at the same time, the comparison of results obtained across different devices? Even if the interest for these themes exists already, and even if many studies have been carried on, these are still quite recent and unexplored topics of research, and much more needs to be done about them. Moreover, technology is evolving so quickly that research results also have to be updated more and more frequently to obtain and maintain an up-to-date view of the reality. Therefore, we need longer time series to track the different phenomena in the future. Furthermore, some of the data we used in this work were not specifically planned to be used for that type of analysis when they were collected. This means that we had to adapt the analyses to the information that was available. Nevertheless, in the future, data could be collected in a more systematic way, and data collection could be planned in advance, such that more precise and/or more complete information becomes available. Previous results, including ours, are also focused on a limited number of countries. Research should be extended to more and more contexts, since we have noticed that the situation clearly varies across countries.

\section{Appendix}

\begin{tabular}{|l|l|r|r|r|r|r|}
\hline & & \multicolumn{1}{c|}{ Q1-13 } & Q2-13 & Q3-13 & Q4-13 & \multicolumn{1}{c|}{ Q1-14 } \\
\hline \multirow{2}{*}{ Argentina } & PC,T & 3,513 & 1,985 & 328 & 8,277 & 3,830 \\
\cline { 2 - 7 } & $\mathrm{S}$ & 417 & 1,472 & 13,220 & 11,245 & 2,663 \\
\hline \multirow{2}{*}{ Brazil } & PC,T & 4,994 & 8,117 & 4,149 & 12,253 & 15,962 \\
\cline { 2 - 7 } & $\mathrm{S}$ & 63 & 75 & 30,265 & 1,833 & 1,930 \\
\hline \multirow{2}{*}{ Chile } & PC,T & 1,567 & 1,811 & 765 & 7,641 & 1,578 \\
\cline { 2 - 7 } & $\mathrm{S}$ & 13 & 263 & 2,737 & 2,903 & 263 \\
\hline
\end{tabular}

(Continued) 


\begin{tabular}{|l|l|r|r|r|r|r|}
\hline \multirow{2}{*}{ Colombia } & PC,T & 2,797 & 3,080 & 799 & 7,862 & 2,935 \\
\cline { 2 - 7 } & $\mathrm{S}$ & 238 & 461 & 5,848 & 2,804 & 773 \\
\hline \multirow{2}{*}{ Spain } & $\mathrm{PC}, \mathrm{T}$ & $\mathrm{NA}$ & 34,493 & 4,323 & 63 & 5,866 \\
\cline { 2 - 7 } & $\mathrm{S}$ & 783 & 2,654 & 218 & 248 & 3,817 \\
\hline \multirow{2}{*}{ Mexico } & $\mathrm{PC}, \mathrm{T}$ & 16,937 & 7,133 & 4,015 & 1,439 & 5,463 \\
\cline { 2 - 7 } & $\mathrm{S}$ & 674 & 666 & 7,117 & 4,535 & 605 \\
\hline \multirow{2}{*}{ Portugal } & $\mathrm{PC}, \mathrm{T}$ & 919 & 4,596 & 1,512 & 266 & 187 \\
\cline { 2 - 7 } & $\mathrm{S}$ & 827 & 136 & 1,394 & 3,658 & 1,281 \\
\hline
\end{tabular}

Appendix 1: Access to mobile devices: number of observations in each country (by quarter-year); Note: $\mathrm{PC}=$ desktop + laptop; $\mathrm{T}=$ tablet; $\mathrm{S}=$ smartphone.

\section{Acknowledgements}

The authors would like to acknowledge the contribution of the European Network WebDataNet (COST Action IS1004, http://webdatanet.cbs.dk/). We are also very grateful to Netquest for providing us with the necessary data and to the University of Bergamo (this research has been partially supported by the $60 \%$ University funds).

\section{References}

Cisco VNI Mobile. (2014). Cisco Visual Networking Index: Global Mobile Data Traffic Forecast Update, 2013-2018. Retrieved October 2014 from http:// www.cisco.com/c/en/us/solutions/collateral/service-provider/visualnetworking-index-vni/white_paper_c11-520862.html

de Bruijne, M., \& Wijnant, A. (2013). Comparing survey results obtained via mobile devices and computers: An experiment with a mobile web survey on a heterogeneous group of mobile devices versus a computer assisted web survey. Social Science Computer Review, 31, 483-505.DOI: http://dx.doi. org/10.1177/0894439313483976

Eurobarometer. (2012). E-Communication Household Survey - Special Eurobarometer 381 report. Retrieved October 2014 from http://ec.europa.eu/public_ opinion/archives/ebs/ebs_381_en.pdf

Fuchs, M., \& Busse, B. (2009). The coverage bias of mobile web surveys across European countries. International Journal of Internet Science, 4, 21-33.

Internet World Stats. (2014). Retrieved July and September 2014 from http:// www.internetworldstats.com

King, G., \& Zeng, L. (1999a). Logistic Regression in Rare Events Data. Department of Government, Harvard University. Retrieved from http://GKing. Harvard.Edu 
King, G., \& Zeng, L. (1999b). Estimating Absolute, Relative, and Attributable Risks in Case-Control Studies. Department of Government, Harvard University. Retrieved from http://GKing.Harvard.Edu

KPCB. (2014). Internet Trends 2014 - Code Conference. Retrieved October 2014 from http://www.slideshare.net/kleinerperkins/internet-trends-201405-28-14-pdf

Nielsen Mobile. (2008). Critical mass: The worldwide state of the mobile Web. Nielsen Company.

Okazaki, S. (2007). Assessing mobile-based online surveys: Methodological considerations and pilot study in an advertising context. International Journal of Market Research, 49, 651-675.

Smart Insights. (2014). 21 Internet trends from the annual KPCB trends report. Retrieved October 2014 from http://www.smartinsights.com/digitalmarketing-strategy/internet-trends-2014-mary-meeker/

StatCounter Global Stats. (2013). Mobile vs. desktop. Retrieved July 2014 from http://gs.statcounter.com/\#mobile_vs_desktop-ww-monthly-201201201309

StatCounter Global Stats. (2014). Retrieved October 2014 from http://gs. statcounter.com/

Statista. (2014). Global fixed broadband and mobile internet penetration 2008-2017. Retrieved October 2014 from http://www.statista.com/statistics/ 280430/worldwide-fixed-broadband-and-mobile-internet-penetration/

Statistics Netherlands. (2012). Mobile internet use continues to grow. [Press release], PB12-060, 23 October 2012. Retrieved June 2, 2013, from http:// www.cbs.nl/en-GB/menu/themas/vrije-tijd-cultuur/publicaties/artikelen/ archief/2012/2012-060-pb.htm

Tomz, M., King, G., \& Zeng, L. (1999). RELOGIT: Rare Events Logistic Regression, Version 1.1. Cambridge, MA: Harvard University, October 1. Retrieved from http://gking.harvard.edu/ 